\title{
Erratum to: Natural radioactivity measurements and dose assessments in sand samples collected from Zonguldak beaches in Turkey
}

Hüseyin Aytekin • Mustafa Çağatay Tufan •

Ceyhun Küçük

Published online: 3 January 2015

(C) Akadémiai Kiadó, Budapest, Hungary 2014

\section{Erratum to: J Radioanal Nucl Chem}

\section{DOI 10.1007/s10967-014-3819-1}

In the original publication, values of Fig. 4 are not consistent with that of Table 1. Therefore, the corrected Fig. 4 is given as below:

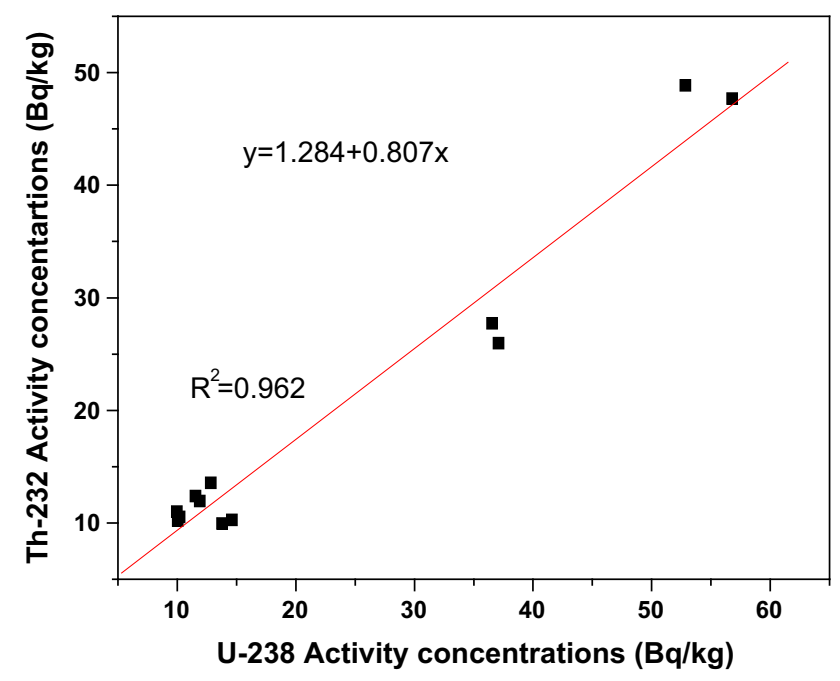

Fig. 4 Correlation between ${ }^{232} \mathrm{Th}$ and ${ }^{238} \mathrm{U}$ activity concentrations in the sand samples from Zonguldak beaches

The online version of the original article can be found under doi:10.1007/s10967-014-3819-1.

H. Aytekin $(\square) \cdot$ C. Küçük

Department of Physics, Bülent Ecevit University,

67100 Zonguldak, Turkey

e-mail: huseyinaytekin@gmail.com

M. Ç. Tufan

Department of Physics, Ondokuz Mayıs University,

Samsun 55139, Turkey 